\title{
An Open Rectifier Potassium Channel with Two Pore Domains in Tandem Cloned from Rat Cerebellum
}

\author{
Dmitri Leonoudakis, ${ }^{1}$ Andrew T. Gray, ${ }^{1}$ Bruce D. Winegar, ${ }^{1}$ Christoph H. Kindler, ${ }^{1}$ Masato Harada, ${ }^{1}$ \\ Donald M. Taylor, ${ }^{1}$ Raymond A. Chavez, ${ }^{2}$ John R. Forsayeth, ${ }^{2}$ and C. Spencer Yost ${ }^{1}$ \\ ${ }^{1}$ Department of Anesthesia, University of California San Francisco, San Francisco, California 94143-0542, and ${ }^{2 N e u r e x}$ \\ Corporation, Menlo Park, California 94025
}

\begin{abstract}
Tandem pore domain $\mathrm{K}^{+}$channels represent a new family of ion channels involved in the control of background membrane conductances. We report the structural and functional properties of a TWIK-related acid-sensitive $\mathrm{K}^{+}$channel (rTASK), a new member of this family cloned from rat cerebellum. The salient features of the primary amino acid sequence include four putative transmembrane domains and, unlike other cloned tandem pore domain channels, a PDZ (postsynaptic density protein, disk-large, zo-1) binding sequence at the $C$ terminal. rTASK has distant overall homology to a putative Caenorhabditis elegans $\mathrm{K}^{+}$channel and to the mammalian clones TREK-1 and TWIK-1. rTASK expression is most abundant in rat heart, lung, and brain. When exogenously expressed in Xenopus oocytes, rTASK currents activate instantaneously, are noninacti-
\end{abstract}

vating, and are not gated by voltage. Because rTASK currents satisfy the Goldman-Hodgkin-Katz current equation for an open channel, rTASK can be classified an open rectifier. Activation of protein kinase A produces inhibition of rTASK, whereas activation of protein kinase $C$ has no effect. rTASK currents were inhibited by extracellular acidity. rTASK currents also were inhibited by $\mathrm{Zn}^{2+}\left(\mathrm{IC}_{50}=175 \mu \mathrm{M}\right)$, the local anesthetic bupivacaine $\left(\mathrm{IC}_{50}=68 \mu \mathrm{M}\right)$, and the anti-convulsant phenytoin $(\sim 50 \%$ inhibition at $200 \mu \mathrm{M})$. By demonstrating open rectification and open probability independent of voltage, we have established that rTASK is a baseline potassium channel.

Key words: potassium channel; open rectifier; local anesthetics; pH; cloning; cerebellum; Xenopus oocyte; baseline channel
Potassium channels are pore-forming integral membrane proteins that selectively pass $\mathrm{K}^{+}$across cellular membranes. These channels are involved in a wide variety of cellular processes, including control of the resting membrane potential, $\mathrm{K}^{+}$homeostasis, neuronal firing, and signal transduction. $\mathrm{K}^{+}$channel physiology is therefore diverse and reflected in well-defined structural and functional differences (Hille, 1992; Christie, 1995). However, all $\mathrm{K}^{+}$channels cloned previously contain at least one signature sequence, the pore $(\mathrm{P})$ or $\mathrm{H} 5$ region, that is thought to line the ion conducting pathway and is critical for determining the $\mathrm{K}^{+}$selectivity of conduction (Durell and Guy, 1992; Jan and Jan, 1992; MacKinnon, 1995).

Recently, a new family of $\mathrm{K}^{+}$channels has been identified, with members having two $\mathrm{P}$ domains in tandem within their primary amino acid sequences (Ketchum et al., 1995). The cloned members of this family are not voltage-gated and may contribute to leak currents setting the membrane potential. TOK1, from the budding yeast Saccharomyces cerevisiae, was the first channel of this type to be cloned (Ketchum et al., 1995) and, by hydropathy analysis, displays eight transmembrane domains. Other cloned

Received Sept. 4, 1997; revised Nov. 12, 1997; accepted Nov. 13, 1997.

This research was supported by the University of California, San Francisco, Research Evaluation and Allocation Committee Grant (A.T.G.), National Institutes of Health Grants GMS-51372 (C.S.Y.) and GM-08440 (D.M.T.), and the Foundation for Anesthesia Education and Research Young Investigator Award (C.S.Y.). We acknowledge Fang Chang for his assistance in sequencing rTASK and Winifred von Ehrenburg for editorial assistance. We also thank Dr. Steven Goldstein for his generous gift of expression plasmids for ORK1 and TOK1.

D.L. and A.T.G. contributed equally to this work.

Correspondence should be addressed to Dr. C. Spencer Yost, Department of Anesthesia, University of California San Francisco, 513 Parnassus Avenue, S-261, Box 0542, San Francisco, CA 94143-0542.

Copyright (C) 1998 Society for Neuroscience $\quad 0270-6474 / 98 / 180868-10 \$ 05.00 / 0$ tandem pore domain $\mathrm{K}^{+}$channels appear to have four transmembrane domains and include the weak inward rectifier TWIK-1 (cloned from both human and mouse) (Lesage et al., 1996b, 1997), the mammalian outward rectifier TREK-1 (Fink et al., 1996), and the open rectifier ORK1 (cloned from Drosophila) (Goldstein et al., 1996). TW IK-1 is highly expressed in hippocampus and cerebral cortex and shares $28 \%$ homology with the outward rectifier TREK-1 that is also found in hippocampus, cerebral cortex, and cerebellum. These channels may be the first cloned examples of a large family of $\mathrm{K}^{+}$channels, as evidenced by the recent identification of at least 23 tandem pore domain $\mathrm{K}^{+}$ channel genes from sequences derived from the Caenorhabditis elegans genome project (Wei et al., 1996).

Using $\mathrm{K}^{+}$channel P region homology and BLAST (basic local alignment search tool), we identified and cloned a cDNA from a rat cerebellum library that encodes a member of the tandem pore domain $\mathrm{K}^{+}$channel family. When this member is expressed in Xenopus oocytes, functional $\mathrm{K}^{+}$channels are produced that exhibit open rectification, noninactivation, and marked sensitivity to extracellular $\mathrm{pH}$ and local anesthetics. In addition, this new member is the first cloned tandem pore domain $\mathrm{K}^{+}$channel to contain a predicted motif for synaptic localization by postsynaptic density protein. Because of the structural homology with recently published full-length human and partial mouse clones (Duprat et al., 1997), we have named our rat clone rTASK, for TWIKrelated acid-sensitive $\mathrm{K}^{+}$channel.

\section{MATERIALS AND METHODS}

Northern blots. A 400 base pair (bp) restriction fragment corresponding to the entire cloned sequence from accession number W36914 expressed sequence tag (EST) was generated using Eco RI and NotI. This fragment was randomly primed (RadPrime DNA labeling system; GIBCO BRL, 
Grand Island, NY) with $\left[\alpha_{-}{ }^{32} \mathrm{P}\right] \mathrm{dCTP}$ (Amersham, Arlington Heights, IL) included in the reaction mixture to produce a labeled probe for hybridization against commercially available human brain and rat multiple tissue Northern blots (Clontech, Palo Alto, CA) and an additional blot of rat cerebellar RNA alone. A labeled control probe was made in the same way by randomly priming the sequence for $\beta$-actin. The blots were hybridized with probe at $65^{\circ} \mathrm{C}$ overnight in ExpressHyb hybridization solution (Clontech), washed three times with $2 \times \mathrm{SSC}$ and $0.05 \%$ SDS at room temperature, and washed twice with $0.1 \times$ SSC and $0.1 \%$ SDS at $55^{\circ} \mathrm{C}$ for $20 \mathrm{~min}$ each. Autoradiographs were made by exposing the blots to x-ray film at $-80^{\circ} \mathrm{C}$.

Library construction and screening. mRNA was isolated directly from adult rat cerebellum (Fast Track 2.0; Invitrogen, San Diego, CA) and used to construct an oligo-dT-primed cDNA library cloned into the UniZAP XR phage vector (Stratagene, La Jolla, CA). One million phage clones were screened. Plaques were transferred to charged nylon membranes (MSI, Westboro, MA) and hybridized at $65^{\circ} \mathrm{C}$ overnight with the $\alpha^{-32}$ P-labeled EcoRI-NotI 400 bp EST fragment in ExpressHyb hybridization solution. Membranes were washed three times with $2 \times$ SSC and $0.05 \%$ SDS at room temperature, washed twice with $0.1 \times$ SSC and $0.1 \%$ $\mathrm{SDS}$ at $55^{\circ} \mathrm{C}$ for $20 \mathrm{~min}$ each, and exposed to $\mathrm{x}$-ray film for $72 \mathrm{hr}$ at $-80^{\circ} \mathrm{C}$. Positive clones were isolated and excised from the UniZAP XR phage vector into pBluescriptSK (Stratagene).

Sequence analysis. The largest positive clone ( $2.1 \mathrm{~kb}$ insert) was sequenced on both strands using a dye terminator kit with an automated sequencer (Applied Biosystems, Foster City, CA). Analyses of DNA and predicted protein sequences were performed using Lasergene (DNASTAR, Madison, WI). Protein motifs were identified using the ExPASy server (University of Geneva, Switzerland) to search the Prosite database.

Transcript preparation. The plasmids containing the rTASK open reading frame, ORK1 (Goldstein et al., 1996), and TOK1 (Ketchum et al., 1995) were linearized by restriction digestion, purified with phenol and chloroform, and used as template. Capped transcript was prepared using the T3 and T7 mMessage mMachines (Ambion, Austin, TX). cRNA was precipitated with lithium chloride and resuspended in oocyte saline (OS; composition in $\mathrm{mM}, 100 \mathrm{KCl}$ and $20 \mathrm{NaCl}$ in diethylpyrocarbonatetreated water) to a final concentration of $\sim 0.5 \mathrm{mg} / \mathrm{ml}$.

Oocyte removal and injection. These studies were approved by the University of California San Francisco Committee on Animal Research. Methods used for oocyte preparation were similar to those described previously (Quick and Lester, 1994). Adult female Xenopus laevis were anesthetized in $0.3 \%$ 3-aminobenzoic acid ethylester on ice for $30 \mathrm{~min}$. After removal, oocytes were incubated with gentle agitation in oocyte Ringer's solution with $\mathrm{Mg}^{2+}$ (OR-Mg; composition in $\mathrm{mM}, 82 \mathrm{NaCl}, 2$ $\mathrm{KCl}, 5 \mathrm{HEPES}$, and $20 \mathrm{MgCl}_{2}, \mathrm{pH} 7.4$ ) with $2 \mathrm{mg} / \mathrm{ml}$ collagenase A (Boehringer Mannheim, Indianapolis, IN) at room temperature, washed twice with enzyme-free OR-Mg, washed twice with modified Barth's solution with HEPES [composition in $\mathrm{mM}, 88 \mathrm{NaCl}, 1 \mathrm{KCl}, 10 \mathrm{HEPES}$, $7 \mathrm{NaHCO}_{3}, 1 \mathrm{CaCl}_{2}$, and $\left.1 \mathrm{Ca}\left(\mathrm{NO}_{3}\right)_{2}, \mathrm{pH} 7.0\right]$, and then selected (stage $\mathrm{V}$ and $\mathrm{VI}$ only) for injection. On the same day as isolation, oocytes were injected with 5-10 ng of either rTASK, ORK1, or TOK1 cRNA or with OS as control. After injection, oocytes were maintained in modified Barth's solution with HEPES with $50 \mathrm{mg} / \mathrm{ml}$ gentamycin, $2.5 \mathrm{~mm}$ sodium pyruvate, $5 \%$ heat-inactivated horse serum, and $5 \mathrm{~mm}$ theophylline at $18^{\circ} \mathrm{C}$ with gentle rotation.

Two-electrode voltage-clamp recordings. All electrophysiology experiments were performed at room temperature $\left(21-23^{\circ} \mathrm{C}\right) 1-3 \mathrm{~d}$ after injection. rTASK, ORK1, and TOK1 currents were measured by twoelectrode voltage clamp (Axoclamp 2A; Axon Instruments, Foster City, $\mathrm{CA})$. Microelectrodes were backfilled with $3 \mathrm{M} \mathrm{KCl}$ and had resistances of $0.3-1.5 \mathrm{M} \Omega$. Pulse protocols were applied from a holding potential of $-80 \mathrm{mV}$ using $1 \mathrm{sec}$ voltage pulse steps ranging from -140 to $+40 \mathrm{mV}$ in $20 \mathrm{mV}$ increments, with $1.5 \mathrm{sec}$ interpulse intervals. Except where noted, all two-electrode voltage-clamp experiments were performed using frog Ringer's solution (composition in mM, $115 \mathrm{NaCl}, 2.5 \mathrm{KCl}, 1.8$ $\mathrm{CaCl}_{2}$, and 10 HEPES, $\mathrm{pH}$ 7.6) as perfusate. Recordings were obtained in a $25 \mu \mathrm{l}$ recording chamber at flow rates of 3-5 ml/min. Saline-injected oocytes were used as controls, undergoing the same treatments as transcript-injected oocytes. To quantify responses, we averaged leakage currents of saline-injected oocytes and subtracted these averages from currents of rTASK oocytes. For most experiments, signals were filtered using an eight pole low-pass Bessel filter (Frequency Devices, Haverhill, MA) set at a $40 \mathrm{~Hz}$ cutoff before sampling at $100 \mathrm{~Hz}$. In some instances, signals were filtered at $100 \mathrm{~Hz}$ before sampling at $1 \mathrm{kHz}$.
Single-channel recordings. Standard methods were used to record single-channel activity from cell-attached or excised patches according to the technique described by Hamill et al. (1981). Patch electrodes were pulled from borosilicate capillary tubes, the shanks were coated with Sylgard (Dow Corning, Midland, MI), and the tips were heat-polished. Currents were recorded with a List EPC-7 amplifier and digitally stored on videotape at a sample rate of $44.1 \mathrm{kHz}$. The current records were analyzed on an LSI 11/73 computer (Indec Systems, Capitola, CA) after filtering with an eight pole Bessel filter $(-3 \mathrm{~dB}$ at $2 \mathrm{kHz})$ and sampling at $10 \mathrm{kHz}$. All experiments were performed at room temperature (21$23^{\circ} \mathrm{C}$ ). Before recordings were performed, the oocyte vitelline membrane was removed with a pair of fine forceps after a 10 min incubation in hypertonic saline (composition in mM, 200 potassium aspartate, $20 \mathrm{KCl}$, $1 \mathrm{MgCl}_{2}, 10$ EGTA, and 10 HEPES, pH 7.4).

rTASK channels were studied primarily in outside-out patches to control both external and internal solutions and to reduce contamination of records by endogenous mechanosensitive channels (Methfessel et al., 1986). For outside-out patches, the patch electrode filling solution contained (in $\mathrm{mM}$ ): 150 potassium aspartate, 10 HEPES, 4 glucose, 1 EGTA,

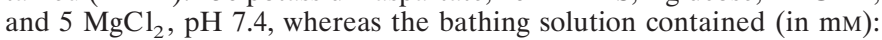
$150 \mathrm{NaCl}, 3 \mathrm{KCl}, 10 \mathrm{HEPES}, 14$ glucose, $2 \mathrm{CaCl}_{2}$, and $1 \mathrm{MgCl}_{2}, \mathrm{pH}$ 7.4. Before seal formation, the voltage offset between the patch electrode and the bath solution was adjusted to produce zero current. The recording micropipette resistances ranged from 3 to $5 \mathrm{M} \Omega$, and seal resistances ranged from 20 to $40 \mathrm{G} \Omega$. The unitary current was determined by positioning a cursor in the center of the open channel noise and measuring the amplitude of the current between the open channel and closed channel level.

Data analysis. Except where noted, data are reported from at least three oocytes and from more than one set of injected oocytes. Mean values are expressed \pm SEM with $n$ values indicating the number of oocytes studied. Statistical significance is defined by $p<0.05$. The Woodhull model (Woodhull, 1973) of voltage-dependent inhibition was used to model $\mathrm{pH}, \mathrm{Zn}^{2+}$, and bupivacaine inhibition of rTASK currents. The Woodhull model parameters were estimated by multiple regression (JMP, SAS Institute, Cary, NC).

\section{RESULTS}

\section{Candidate clone identification}

Pore and adjacent regions of all identified tandem pore domain $\mathrm{K}^{+}$channels were aligned using the MegAlign program (Clustal algorithm; Lasergene; DNASTAR). Consensus protein sequences of each $\mathrm{P}$ domain from these alignments were used to perform BLAST searches of the EST database (Altschul et al., 1990). These searches identified a clone (accession number W36914) from a mouse cDNA library (19.5 days after conception) that contained a novel $\mathrm{P}$ region. This clone was referred to as "EST400" because it contained a 400 bp insert of cDNA. Secondary searches of the EST database revealed three other clones (accession numbers W01960, W99136, and W36852) that formed a contiguous sequence of $901 \mathrm{bp}$. When translated, this contiguous sequence of four ESTs contained an open reading frame (ORF) with two $\mathrm{P}$ regions in tandem. EST400 was then used to probe an adult rat cerebellum cDNA library to identify a full-length sequence. Six positive clones were identified and excised as plasmids with the largest containing a 2.1 kilobase pair (kb) cDNA insert.

\section{Sequence analysis}

The $2.1 \mathrm{~kb}$ insert of this clone was completely sequenced on both strands and found to contain an ORF of 1233 bp encoding a 411 amino acid polypeptide with a calculated molecular weight of 45.3 $\mathrm{kDa}$ that we have termed rTASK (Fig. $1 A$ ). Strong translation initiation sequences were found adjacent to the start codon (Kozak, 1996). A hydrophobicity plot (Kyte-Doolittle method) indicates four potential transmembrane domains, here designated M1-M4 (Fig. 1B). The predicted protein sequence contains two $\mathrm{P}$ domains, P1 located between M1 and M2 and P2 located 

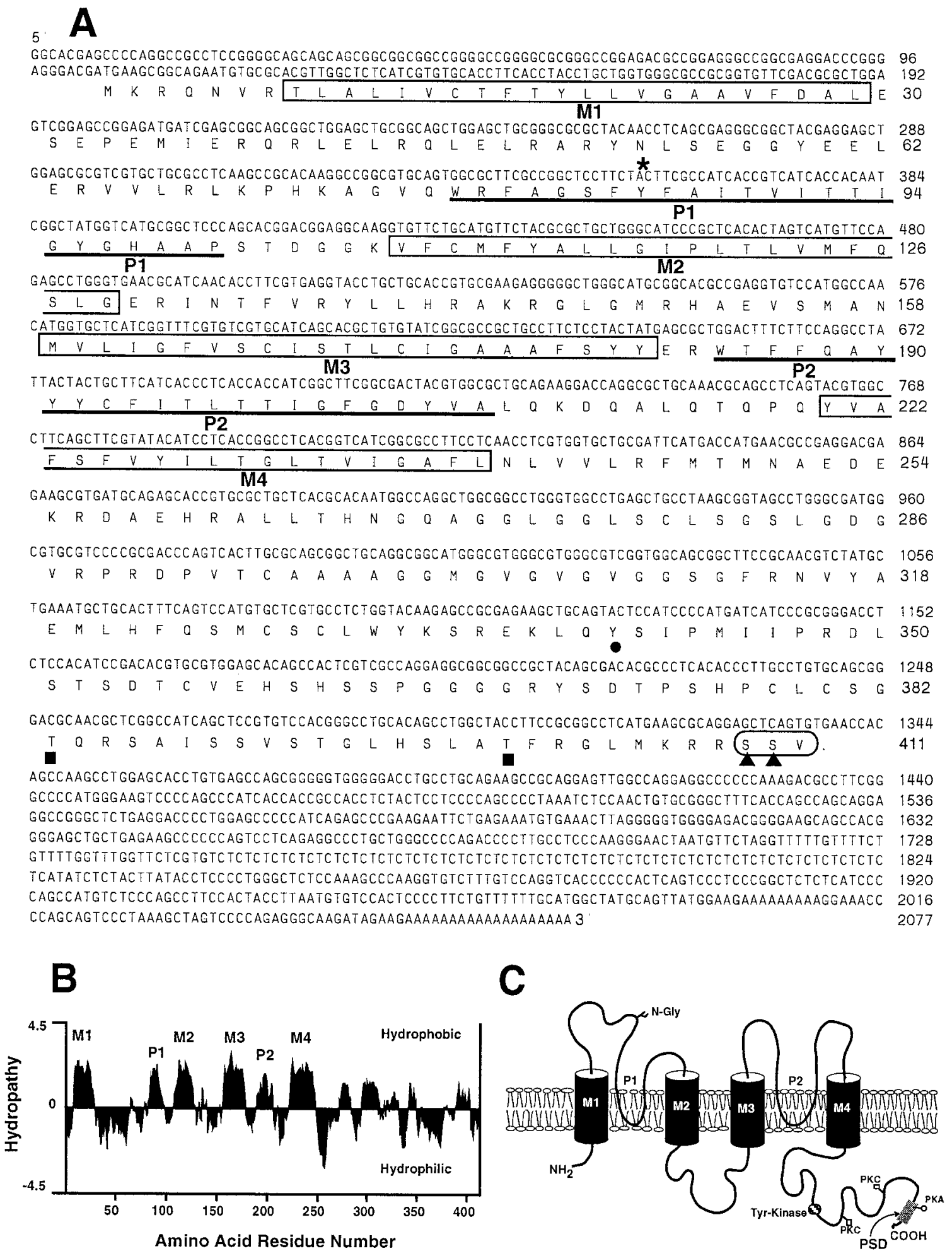

Figure 1. Sequence analysis of rTASK. A, Nucleotide and deduced amino acid sequence of rTASK. The four putative transmembrane domains $(M 1-M 4)$ are enclosed in boxes. Underlined segments indicate pore regions $(P 1, P 2)$. Sites for N-linked glycosylation (asterisk) and phosphorylation by tyrosine kinase (filled circle), protein kinase C (filled squares), and protein kinase A (filled triangles) are indicated. The circled amino acids at the C terminal indicate the postsynaptic density (PSD) binding motif. B. Hydropathy plot showing transmembrane domains $(M 1-M 4)$ and the P regions ( $P 1$, $P 2)$ using the Kyte-Doolittle algorithm. $C$, Predicted transmembrane topology of rTASK with labeled transmembrane domains and pore regions. The GenBank accession number of the rTASK clone is AF031384. 


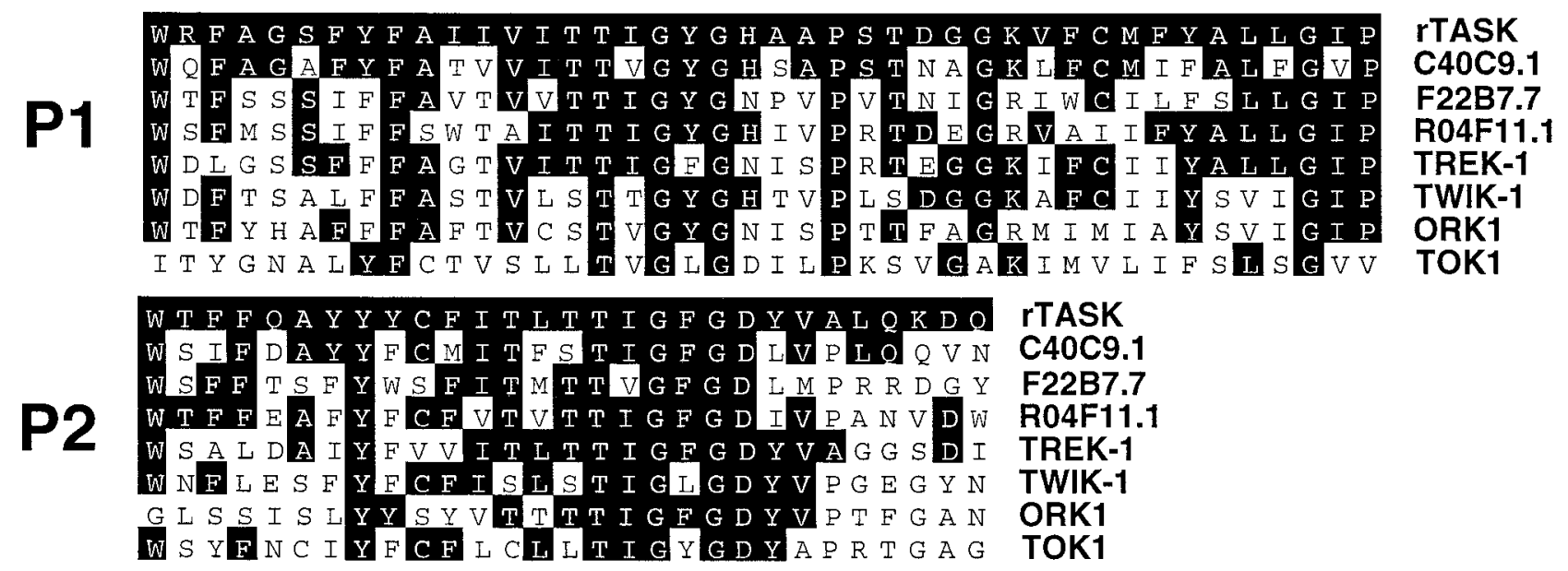

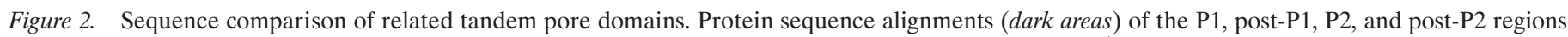

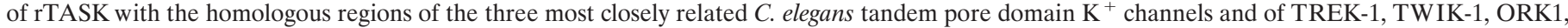
and TOK1 are shown.

between M3 and M4. rTASK does not have an N-terminal signal sequence, suggesting that the $\mathrm{N}$ terminal is intracellular (Walter and Lingappa, 1986). rTASK also contains potential phosphorylation sites for tyrosine kinase, protein kinase $\mathrm{C}$ (PKC), and protein kinase A (PKA). In addition, a PDZ [postsynaptic density protein (PSD), disk-large, zo-1] interaction domain (Kornau et al., 1995; Cohen et al., 1996) occurs at the extreme C terminal (SSV) and overlaps the putative PKA phosphorylation sites.

Figure $1 C$ shows the predicted topology based on these data. Sequence alignment revealed weak homology with two other pore domain $\mathrm{K}^{+}$channels overall (37.1\% similarity with the C. elegans predicted protein C40C9.1; 19.5\% with TREK-1). However, higher level homology appears when the alignments are restricted to the $\mathrm{P} 1$ and $\mathrm{P} 2$ regions (69.0 and $58.6 \%$ similarity for $\mathrm{C} 40 \mathrm{C} 9.1$; 61.9 and $58.6 \%$ for TREK-1; Fig. 2). Residues farther downstream from P1 also show significant conservation with other tandem pore domain clones.

\section{Tissue distribution}

Northern blot analysis of rat mRNA (Fig. 3) showed transcripts of $\sim 4 \mathrm{~kb}$ in heart $\gg$ lung $>$ brain $\gg$ liver, kidney, and skeletal muscle. A transcript corresponding to our cloned sequence could also be detected in rat cerebellum. A human multiple tissue Northern blot, when screened with an rTASK probe, showed abundant expression of three different-sized bands $(2.7,4.4$, and $7 \mathrm{~kb}$ ) in placenta, lung, and pancreas, with only the smaller 2.7 and $4.4 \mathrm{~kb}$ transcripts in heart, brain, and kidney at relatively lower abundance (data not shown).

\section{Functional expression of rTASK channels}

cRNA was transcribed from the plasmid containing rTASK and injected into Xenopus laevis oocytes. Oocytes injected with transcript exhibited large $(0.5-8 \mu \mathrm{A})$ outward noninactivating currents under two-electrode voltage clamp. These currents were not observed in saline-injected or uninjected oocytes. No evidence of inactivation of the channel was observed with long voltage pulses (1-10 sec in duration). Oocytes that expressed rTASK also had more negative resting membrane potentials $(E \mathrm{~m})$ than did control saline-injected oocytes (for rTASK oocytes, $E \mathrm{~m}=-66 \pm 2 \mathrm{mV}$; $n=21$; for control saline-injected oocytes, $E \mathrm{~m}=-33 \pm 4 \mathrm{mV}$; $n=10)$.

To determine the ion selectivity of the channel, we conducted

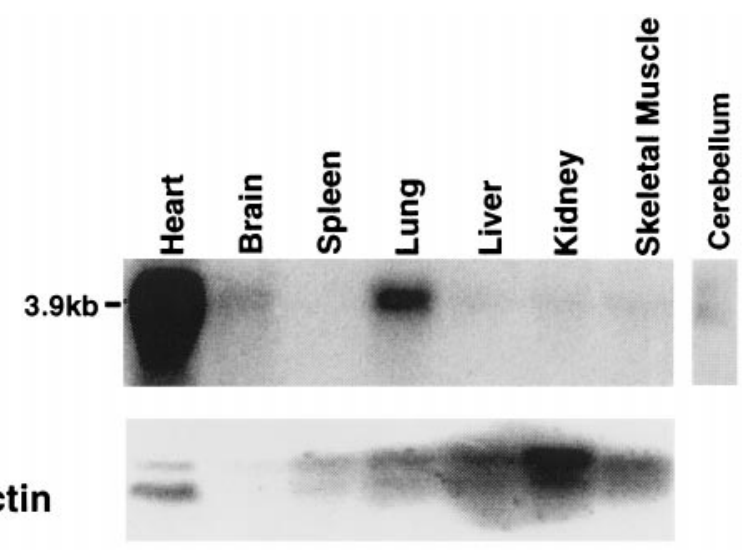

Figure 3. Northern blot analysis of rTASK distribution in adult rat tissue. A rat multiple tissue Northern blot was probed at high stringency with a probe made from the EST400 sequence. The blot was reprobed with a $\beta$-actin cDNA probe for a control. Added lane shows the presence of rTASK transcript in rat cerebellum.

experiments using varying concentrations of extracellular $\mathrm{K}^{+}$. The slope of the plot of reversal potential versus $\mathrm{K}^{+}$concentration was $54 \pm 3 \mathrm{mV}$ per 10 -fold change in $\mathrm{K}^{+}$concentration, close to that predicted for a potassium-selective channel (Fig. 4A). At high levels of extracellular potassium $(100 \mathrm{~mm})$, large inward currents were observed at negative holding potentials of rTASKinjected oocytes, as predicted by the Goldman-Hodgkin-Katz current equation for an open channel (Fig. 4B).

\section{Pharmacology of rTASK}

The pharmacological properties of rTASK expressed in Xenopus oocytes are summarized in Table 1 for a set of $\mathrm{K}^{+}$channel blockers and modulators. We found rTASK was moderately sensitive to inhibition by $\mathrm{Zn}^{2+}$, quinidine, phenytoin, and mast cell degranulating (MCD) peptide. $\mathrm{Zn}^{2+}$ inhibition was dosedependent with an $\mathrm{IC}_{50}$ value of $175 \mu \mathrm{M}$. Likewise, external tetraethylammonium $\left(\mathrm{TEA}^{+}\right)$produced a dose-dependent inhibition over the range from 10 to $100 \mathrm{~mm}$ but did not inhibit more than $\sim 30-40 \%$ of rTASK current. Quinidine, which inhibits TWIK-1 currents by $50 \%$ at $95 \mu \mathrm{M}$ (Lesage et al., 1996b), inhibited rTASK currents $\sim 30 \%$ at $100 \mu \mathrm{M}$. The anti-convulsant phe- 

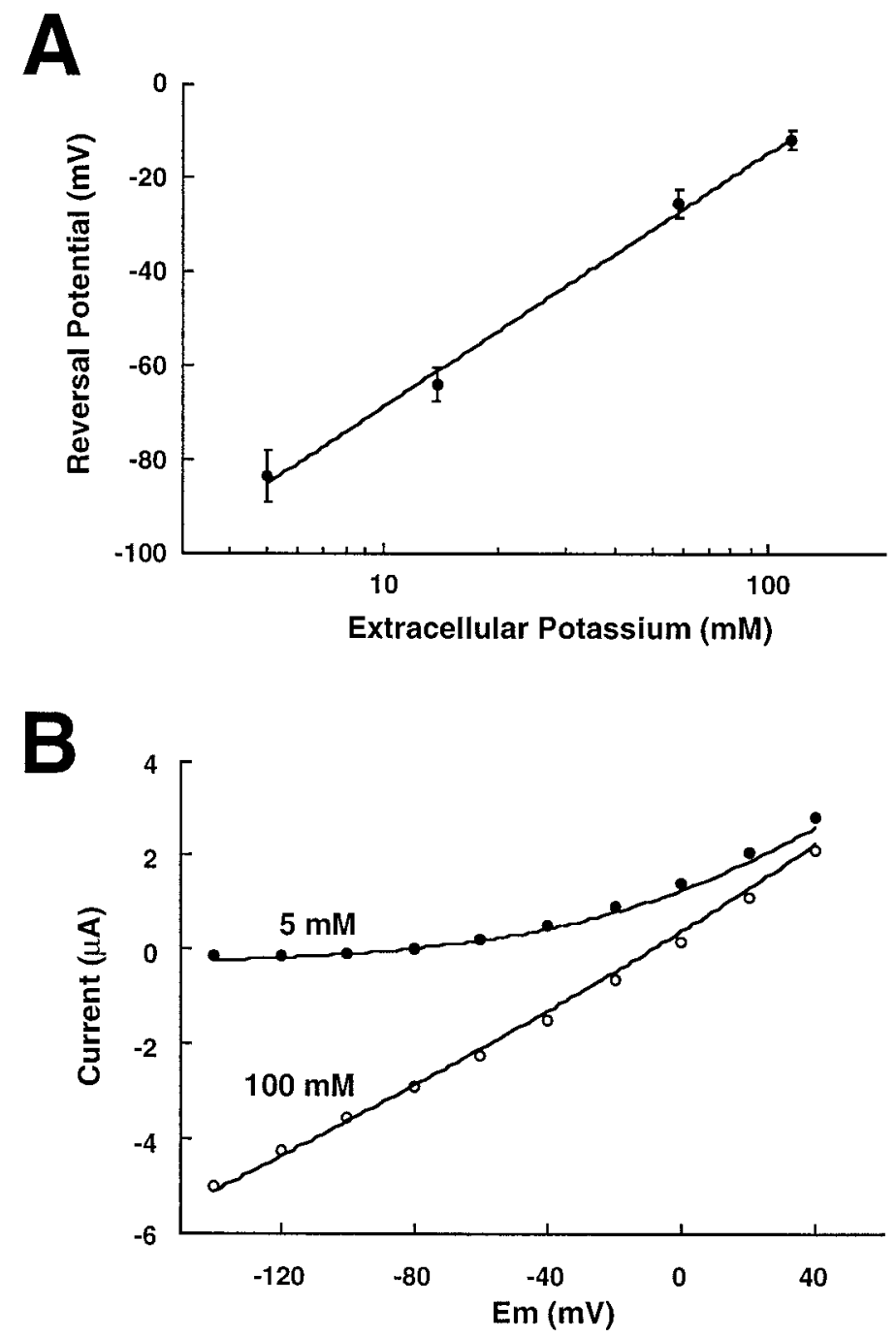

Figure 4. Biophysical properties of rTASK currents in Xenopus oocytes studied with two-electrode voltage clamp. $A$, Reversal potential as a function of extracellular $\mathrm{K}^{+}$for rTASK-expressing oocytes. Reversal potential changed by $54 \pm 3 \mathrm{mV}$ per 10 -fold change in extracellular $\mathrm{K}^{+}$, as estimated with linear regression (regression line shown). $B$, Whole-cell current-voltage relation with either $5 \mathrm{~mm}$ (filled circles) or $100 \mathrm{~mm}$ (open circles) extracellular $\mathrm{K}^{+}$. The current-voltage relations for an open $\mathrm{K}^{+}$. selective channel estimated from the Goldman-Hodgkin-Katz current equation are drawn as solid lines.

nytoin $(200 \mu \mathrm{M})$ in $1 \%$ DMSO (dimethylsulfoxide) inhibited rTASK currents by almost $50 \%$. DMSO alone had a small effect on rTASK currents and on saline-injected oocytes (inhibition of $16 \pm 5 \%$ ).

Several other compounds known to have modulatory effects on $\mathrm{K}^{+}$channels also were examined. Increases in extracellular $\mathrm{Mg}^{2+}$ (up to $10 \mathrm{~mm}$ ) caused minimal inhibition (14\%). Barium produced only minimal rTASK inhibition (19\%) at $100 \mu \mathrm{M}$. Unlike TREK-1, the $\mathrm{K}^{+}$currents of which are inhibited almost completely by $N$-methyl-D-glucamine (NMDG) substitution for $\mathrm{Na}^{+}$ in the external buffer (Fink et al., 1996), rTASK had only weak sensitivity to NMDG substitution, but this inhibition was greater than that for ORK1, which is insensitive to NMDG substitution (Goldstein et al., 1996). rTASK was insensitive or minimally affected $(<15 \%)$ by the following $\mathrm{K}^{+}$channel inhibitors: 4-aminopyridine $(10 \mathrm{~mm})$, agitoxin $(1 \mathrm{nM})$, dendrotoxin $(100 \mathrm{nM})$,
Table 1. Pharmacology of rTASK expressed in Xenopus oocytes

\begin{tabular}{lll} 
Treatment & Response (\%) & $n$ \\
\hline Zinc $100 \mu \mathrm{M}$ & $61 \pm 9$ & 6 \\
TEA $100 \mathrm{mM}$ & $67 \pm 5$ & 4 \\
Quinidine $100 \mu \mathrm{M}$ & $71 \pm 4$ & 4 \\
Phenytoin $200 \mu \mathrm{M}$ & $53 \pm 5$ & 5 \\
MCD peptide $1 \mu \mathrm{M}$ & $67 \pm 11$ & 4 \\
Magnesium $10 \mathrm{mM}$ & $86 \pm 3$ & 3 \\
Barium $100 \mu \mathrm{M}$ & $81 \pm 1$ & 4 \\
NMDG substitution & $72 \pm 2$ & 3 \\
DNP $1 \mathrm{~mm}$ & $43 \pm 5$ & 4 \\
Lidocaine $1 \mathrm{mM}$ & $39 \pm 16$ & 4 \\
QX314 $1 \mathrm{mM}$ & $92 \pm 4$ & 3 \\
Ethanol $170 \mathrm{mM}$ & $59 \pm 20$ & 3 \\
Forskolin $10 \mu \mathrm{M}+$ IBMX $1 \mathrm{mM}$ & $58 \pm 4$ & 6 \\
\hline
\end{tabular}

Studies were performed under two-electrode voltage clamp in frog Ringer's solution at $\mathrm{pH}$ 7.6. Response is defined as the current measured for the -80 to $+40 \mathrm{mV}$ pulse during the treatment condition compared with control. Mean values are shown with SE ( $n$ values listed indicate the number of oocytes studied). All of the compounds in the table were applied in the perfusate. NMDG experiments were performed with a perfusion solution where NMDG was substituted for sodium. DNP $(2,4$ dinitrophenol) and forskolin/IBMX were applied for 6-10 min before application of the voltage pulse. Other compounds were applied for $2 \mathrm{~min}$ before the pulse protocol.

margatoxin (10 nM), charybdotoxin (200 nM), and glibenclamide $(30 \mu \mathrm{M})$. The $\mathrm{K}^{+}$channel opener cromakalim $(100 \mu \mathrm{M})$ also had minimal effect on rTASK currents.

rTASK currents were reversibly sensitive to changes in extracellular $\mathrm{pH}$. At extracellular $\mathrm{pH}$ 6.4, rTASK currents were suppressed to a level close to the currents of saline-injected oocytes (Fig. $5 A$ ), but further decreases in extracellular $\mathrm{pH}$ did not alter rTASK current. At extracellular $\mathrm{pH}$ values above 7.6, rTASK currents were potentiated (Fig. $5 B, C$ ). The metabolic inhibitor dinitrophenol (DNP), which lowers intracellular $\mathrm{pH}$ by uncoupling the $\mathrm{H}^{+}$gradient in mitochondria (Snoeij et al., 1986), inhibited rTASK currents by $>50 \%$ after 6 min of perfusion (Table 1). The magnitude of this inhibition was similar to that reported for TWIK-1 (Lesage et al., 1996b).

The effects of several anesthetic agents on rTASK were investigated. The local anesthetic bupivacaine showed dose-dependent inhibition of rTASK with an $\mathrm{IC}_{50}$ of $68 \mu \mathrm{M}$ (Fig. 6). Lidocaine also inhibited rTASK, but not as potently as bupivacaine. Interestingly, the positively charged lidocaine analog QX314 had no effect on rTASK currents (Table 1). Ethanol caused dose-dependent inhibition of rTASK with minimal inhibition at a clinical concentration (17 mm, 9\% inhibition) and moderate inhibition at a higher concentration ( $170 \mathrm{~mm}, 41 \%$ inhibition). Neither the volatile general anesthetic isoflurane (0.015-0.03 atm) nor the intravenous anesthetic agent pentobarbital $(200 \mu \mathrm{M})$ had a significant effect on rTASK currents (data not shown).

Figure 7 illustrates the comparative sensitivity of three of the five cloned tandem pore domain $\mathrm{K}^{+}$channels to various modulators. These data were obtained from rTASK, ORK1, and TOK1 channels that were expressed in parallel with the same batch of Xenopus oocytes by injection of in vitro transcript and were exposed to the same experimental conditions. rTASK was significantly more inhibited by decreased extracellular $\mathrm{pH}$ and by local anesthetics than were the other two channels, whereas ORK1 was significantly more inhibited by a concentration of $\mathrm{Zn}^{2+}(100 \mu \mathrm{M})$ that produced only moderate inhibition of TOK1 and rTASK.

Multiple regression was used to estimate $\delta$, the effective elec- 
A
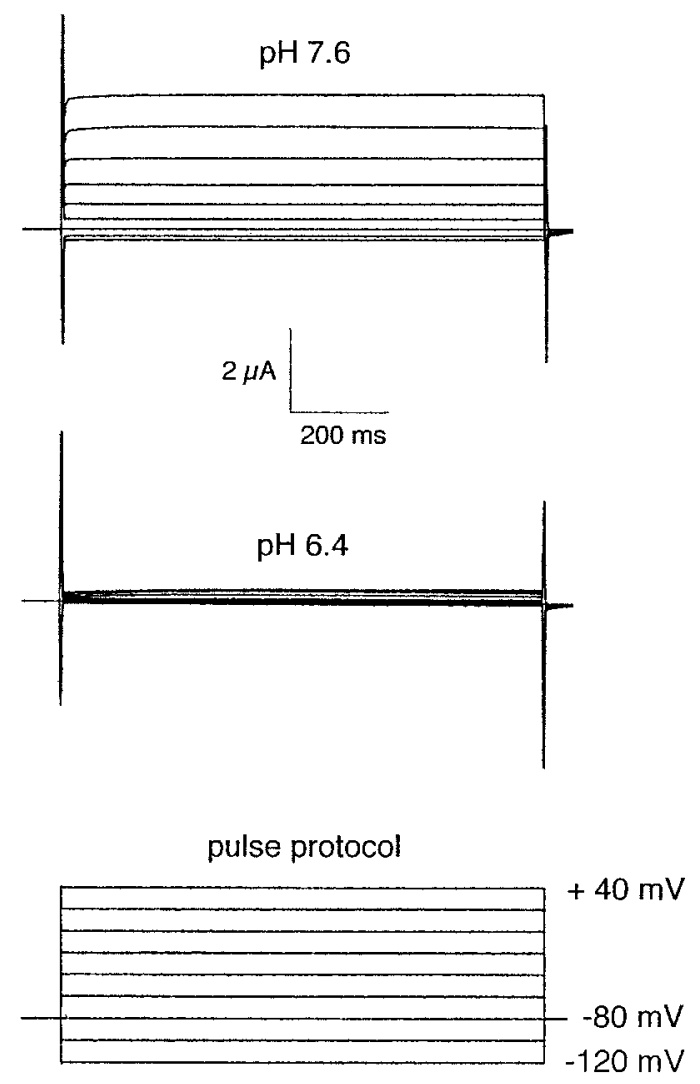

B

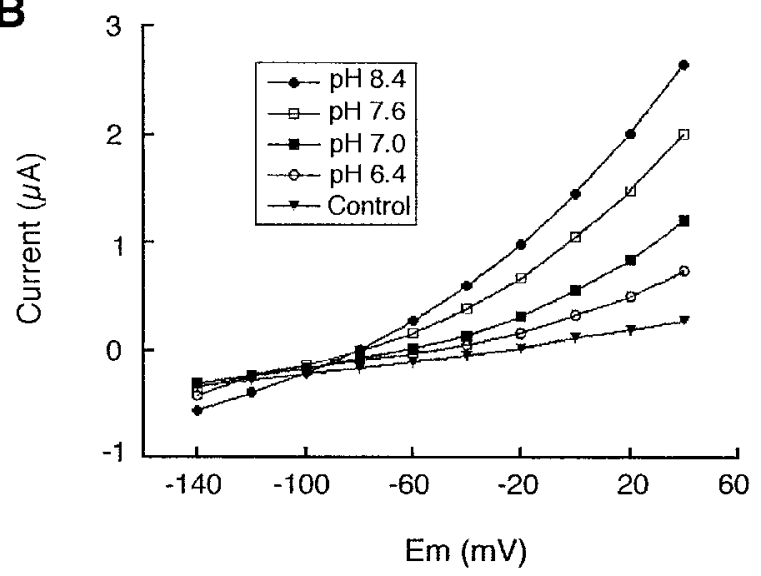

C

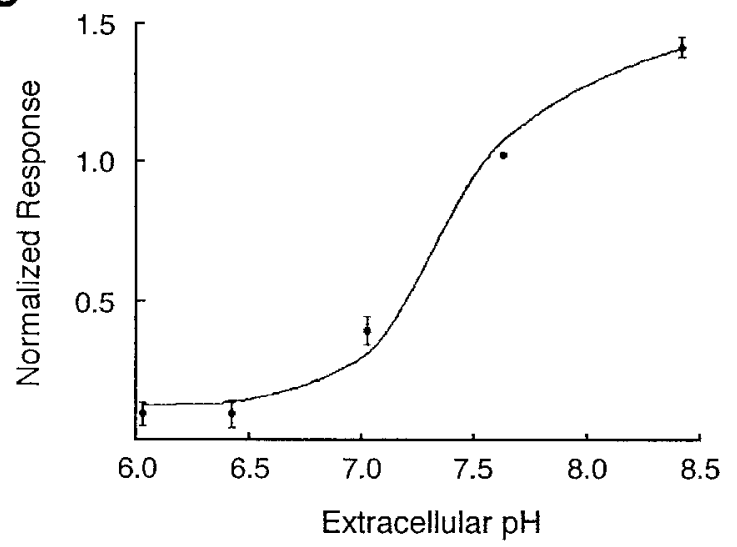

Figure 5. Extracellular pH sensitivity of rTASK. A, Representative current responses from rTASK cRNA-injected oocytes at pH 7.6 and 6.4 (voltage pulses from -120 to $+40 \mathrm{mV}$ ). $B$, Current-voltage curves of rTASK-injected oocytes at several different extracellular $\mathrm{pH}$ values. Currents from control saline-injected oocytes were unchanged over this $\mathrm{pH}$ range. $C$, Effect of extracellular $\mathrm{pH}$ on rTASK currents $(-80$ to $+40 \mathrm{mV}$ pulse). Data have been normalized to currents measured at $\mathrm{pH}$ 7.6. Mean values are shown with the SE.

trical distance to the blocking site, according to a widely used model of voltage-dependent binding (Woodhull, 1973). We found that $\mathrm{pH}$ and $\mathrm{Zn}^{2+}$ inhibited rTASK currents in a voltagedependent manner, with $\delta=0.16 \pm 0.06$ and $0.15 \pm 0.04$, respectively. These estimates suggest that $\mathrm{H}^{+}$and $\mathrm{Zn}^{2+}$ produce block at relatively peripheral sites in the rTASK pore, both located at $\sim 15 \%$ of the potential drop from the membrane surface. However, bupivacaine inhibition was voltageindependent at concentrations as high as $300 \mu \mathrm{M}$.

\section{Regulation by intracellular phosphorylation}

Because the primary amino acid sequence of rTASK possesses target motifs for phosphorylation by PKA and PKC at the $\mathrm{C}$ terminal, we investigated regulation of rTASK by these kinases. The PKC activators phorbol 12,13-dibutyrate (PDBu; $500 \mathrm{~nm}$ ) and phorbol 12-myristate 13-acetate (PMA; $50 \mathrm{nM}$ ) had no effect. However, perfusion of rTASK-expressing oocytes with forskolin and 1-methyl-3-isobutylxanthine (IBMX), which increase intracellular cAMP levels, reduced rTASK currents to $58 \%$ of control (Table 1). These results suggest modulation of rTASK by PKA but not by PKC.

\section{Single-channel properties}

Excised outside-out patches from oocytes injected with rTASK transcript showed noninactivating baseline channels that con- ducted outward currents at depolarized potentials (Fig. 8A). This pattern of channel activity was not observed in saline-injected oocytes. Channel activity did not appear to be altered by patch

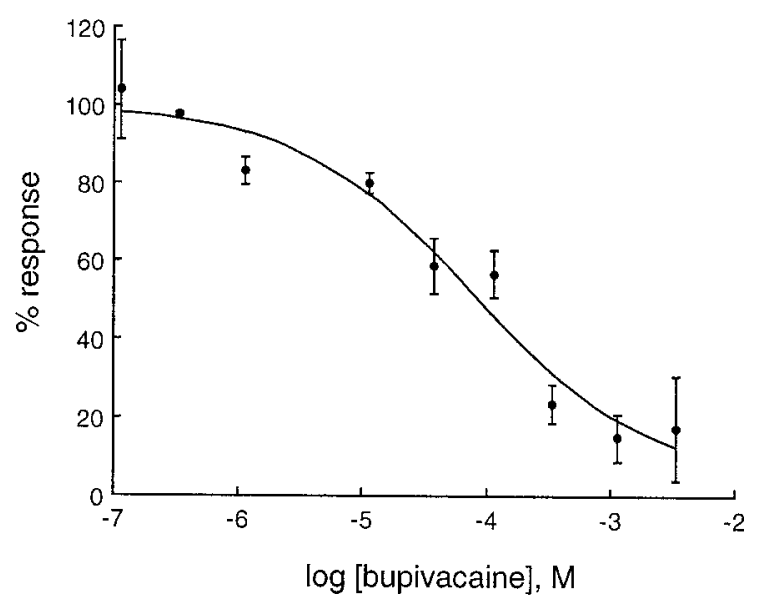

Figure 6. Concentration-response curve for bupivacaine. Currents elicited by the -80 to $+40 \mathrm{mV}$ pulse have been normalized to currents measured before and after bupivacaine application and fit to a logistic function $\left(\mathrm{IC}_{50}=68 \mu \mathrm{M}\right.$; Hill coefficient $\left.=0.6\right)$. 


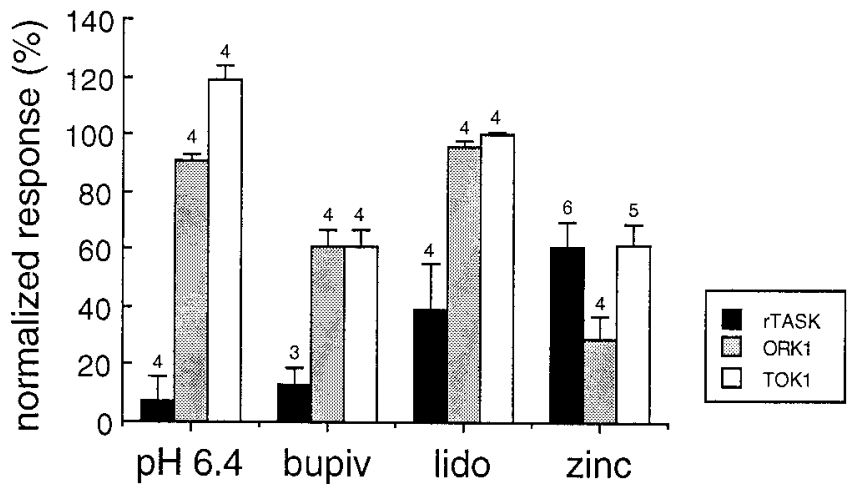

Figure 7. Comparative pharmacology of tandem pore domain $\mathrm{K}^{+}$channels expressed in Xenopus oocytes. Relative responses of three clones (rTASK, ORK1, and TOK1) are compared for several potent modulators (extracellular $\mathrm{pH}$ 6.4, bupivacaine $1 \mathrm{~mm}$, lidocaine $1 \mathrm{mM}$, and $\mathrm{Zn}^{2+} 100$ $\mu \mathrm{M})$. Studies were performed under two-electrode voltage clamp in frog Ringer's solution at $\mathrm{pH}$ 7.6. Response is defined as the current measured for the -80 to $+40 \mathrm{mV}$ pulse during the treatment condition compared with control. Mean values are shown with SE. Numbers over the bars indicate number of experiments.

excision and did not "run down". Inward currents were observed only at extremely hyperpolarized potentials. These lower amplitude inward currents were never observed in patches from salineinjected control oocytes or in patches with no outward currents at positive potentials $(n=10)$. The single-channel currents were well-resolved within the $2 \mathrm{kHz}$ bandwidth of our recording system.

A compressed record of channel activity (Fig. 8B) illustrates the pattern of spontaneous gating, which was characterized by long-duration openings interrupted by short closures. Brief interruptions of current often were present during openings at positive potentials, which could be caused by a blocking ion or a result of the intrinsic gating properties of the channel. rTASK currents were not sensitive to changes in intracellular calcium (data not shown), unlike the M channel (Selyanko and Brown, 1996).

\section{Single-channel current-voltage relation}

Figure $9 A$ shows the current-voltage relations of single rTASK channels recorded with an outside-out patch configuration. Strong outward rectification was evident when the patches were in a $150 \mathrm{~mm} \mathrm{NaCl}$ bath solution (circles). Under these conditions the single-channel conductance at $+20 \mathrm{mV}$ was $\sim 40 \mathrm{pS}$. Outward rectification was reduced when external $\mathrm{Na}^{+}$was partially replaced with $\mathrm{K}^{+}$(triangles), whereas complete replacement with $\mathrm{K}^{+}$shifted the reversal potential to $0 \mathrm{mV}$ and produced a linear $I-V$ relation with a conductance of $\sim 14 \mathrm{pS}$ (squares). The open probability of single rTASK channels did not exhibit any voltage dependence over a wide range of holding potentials (Fig. 9B). The mean open probability for potentials from -10 to $+70 \mathrm{mV}$ was $0.52 \pm 0.03$ (mean $\pm \mathrm{SEM} ; n=34$ ).

\section{DISCUSSION}

rTASK is a new mammalian member of the tandem pore domain $\mathrm{K}^{+}$channel family. Two structural subclasses have been found within this family, one containing eight putative transmembrane domains (TOK1) and another with four putative transmembrane domains (TWIK-1, TREK-1, ORK1, and TASK). A large number of putative tandem pore domain $\mathrm{K}^{+}$channels have been identified as part of the C. elegans genome project, making it likely that many more homologous two-pore domain $\mathrm{K}^{+}$channels will

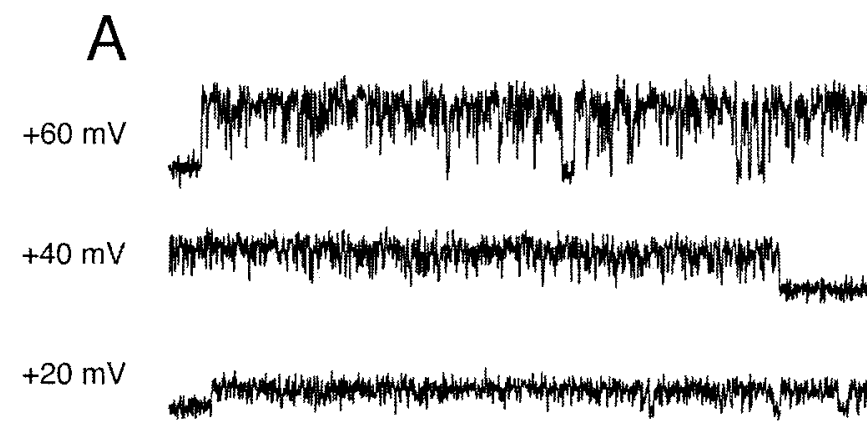

$0 \mathrm{mV}$

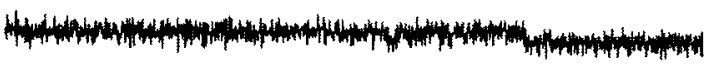

$-160 \mathrm{mV}$

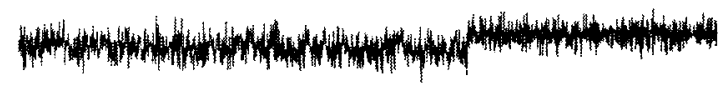

$-200 \mathrm{mV}$

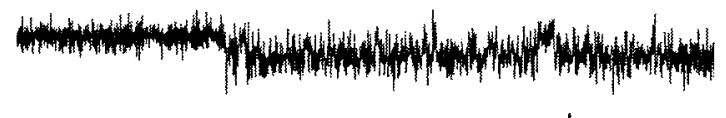

$2 \mathrm{pA} \lcm{20 \mathrm{~ms}}$

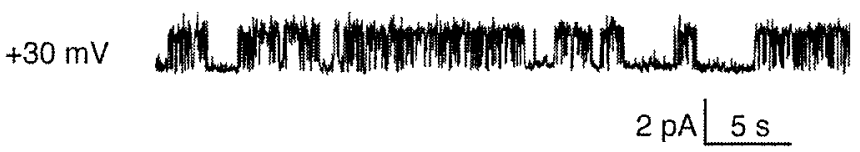

Figure 8. Patch-clamp recordings of rTASK currents expressed in Xenopus oocytes. $A$, Unitary rTASK currents recorded from an outside-out patch at several holding potentials. The recording pipette was filled with $150 \mathrm{~mm} \mathrm{~K}$-aspartate, and the external solution was $150 \mathrm{~mm} \mathrm{NaCl}$. Currents were filtered at $2 \mathrm{kHz}$. B, Compressed records of single rTASK channel activity.

be found in the mammalian genome. All of the putative C. elegans two-pore domain $\mathrm{K}^{+}$channels found thus far have four transmembrane domains (Wei et al., 1996).

By Northern analysis, we found that rTASK is highly expressed in rat heart with lower levels in lung and brain tissue. This pattern of relative expression is opposite that seen with TWIK-1, where high levels of TWIK-1 mRNA can be found in mouse brain but none in mouse heart (Lesage et al., 1996b). A different pattern of expression is also seen with human TASK, where high levels of expression are found in human pancreas and placenta and where brain expression is much higher than heart expression (Duprat et al., 1997). Explanation of these species differences in the tissue distribution of tandem pore domain $\mathrm{K}^{+}$channels must await a better understanding of the physiological role of these channels. The double and triple bands found with the human Northern blots may indicate either splice variants or the presence of a closely related homolog.

TWIK-1 self-associates to form homodimers via a disulfide bridge between subunits (Lesage et al., 1996c) involving cysteine residues between $\mathrm{M} 1$ and $\mathrm{P} 1$. Injection of rTASK transcript alone into Xenopus oocytes gives rise to functional $\mathrm{K}^{+}$channels, suggesting that rTASK channels are homodimeric. rTASK does not have a homologous cysteine or any predicted extracellular cysteine. Therefore, if rTASK forms a disulfide bridge, it must involve cysteine residues currently designated intracellular or intramembranous. 


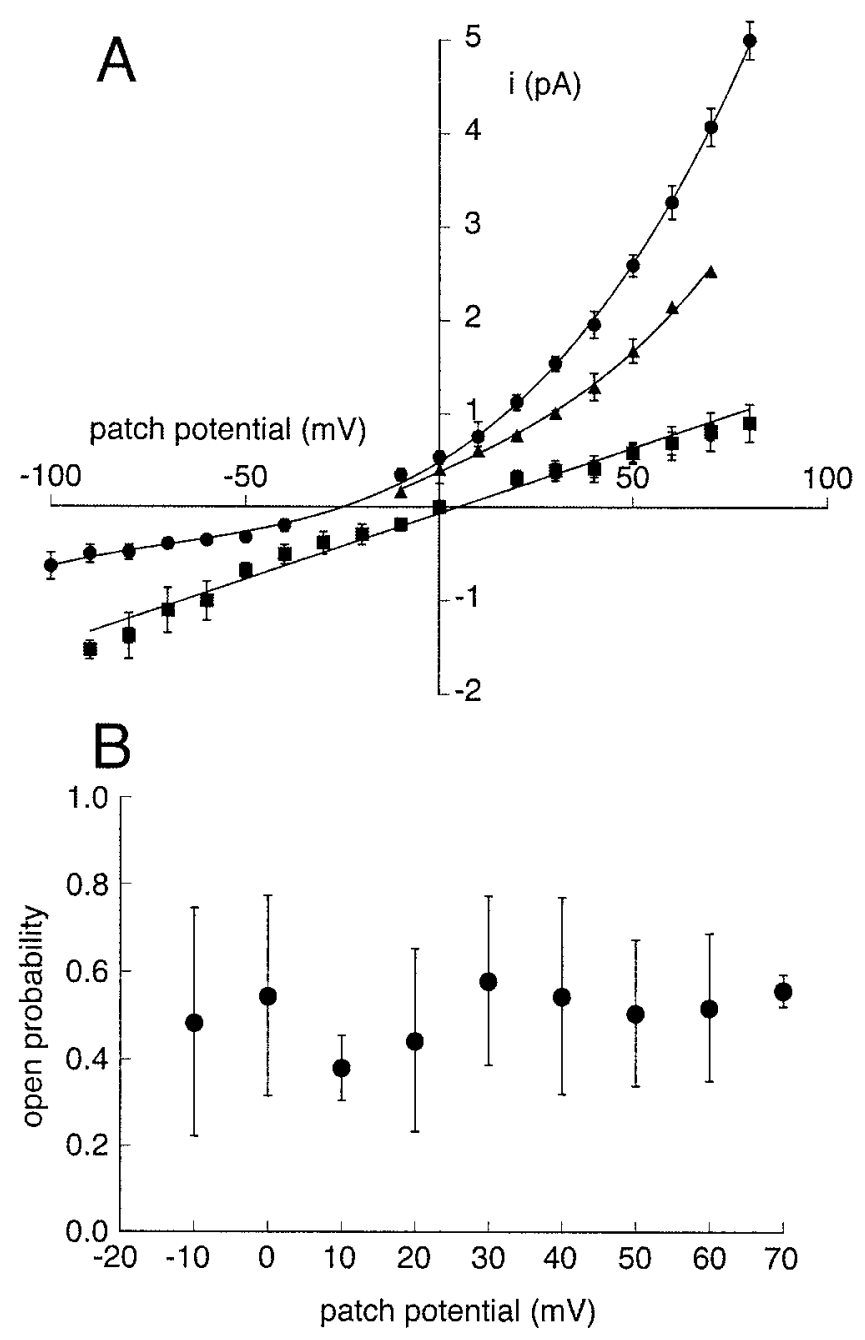

Figure 9. rTASK single-channel properties recorded from outside-out patches. $A$, Single-channel $I-V$ relations. The recordings were made with $150 \mathrm{mM} \mathrm{K}^{+}$in the recording pipette and bath solutions of $150 \mathrm{~mm} \mathrm{NaCl}$ (circles; $n=7$ ), a mixture of $75 \mathrm{mM} \mathrm{Na}^{+}$with $75 \mathrm{~mm} \mathrm{~K}{ }^{+}$(triangles; $n=$ 2), and $150 \mathrm{mM} \mathrm{K}^{+}$(squares; $\left.n=4\right)$. In the presence of symmetrical 150 $\mathrm{mm} \mathrm{K}^{+}$, the $I-V$ relation was best fit to a linear function. Data in the other conditions were fit with third degree polynomial functions, which illustrates the pattern of outward rectification. The unitary current was measured as the amplitude of the current from the closed channel level to a cursor positioned in the center of the open channel noise. Error bars indicate $\mathrm{SD}$ of the mean. $B$, Independence of the open probability of single rTASK channels from the patch potential. The open probabilities are the means from outside-out patches $(n=4)$ recorded with a bath solution of $150 \mathrm{~mm} \mathrm{NaCl}$. Individual values were calculated by setting the single-channel amplitude to unity and integrating records from $30 \mathrm{sec}$ data segments at each voltage. Error bars indicate SDs.

rTASK expression in Xenopus oocytes produced relatively large outward $\mathrm{K}^{+}$currents at depolarized potentials. rTASK currents were observed at all membrane potentials tested and appeared to be noninactivating in the manner of a background or leak $\mathrm{K}^{+}$channel (Hodgkin and Huxley, 1952). These results suggest that rTASK currents may contribute to determining the resting potential of the cell. In addition, as $E_{\mathrm{K}}$ became more positive, inward currents through rTASK channels were correspondingly shifted in a manner resembling the open rectifier properties described previously for ORK1 (Goldstein et al., 1996) that passes large inward currents at high extracellular $\mathrm{K}^{+}$concentrations. This characteristic distinguishes ORK1 and rTASK from TOK1, which does not pass large inward currents (Ketchum et al., 1995; Lesage et al., 1996a). ORK1 and rTASK also are similar in that their activation occurs almost instantaneously, in contrast with TOK1 that exhibits slower activation from a deep closed state (Lesage et al., 1996a).

rTASK currents are highly sensitive to extracellular $\mathrm{pH}$. Low extracellular $\mathrm{pH}(6.0-6.4)$ completely inhibits rTASK $\mathrm{K}^{+}$currents, whereas high extracellular $\mathrm{pH}$ potentiates them. The extracellular $\mathrm{pH}$ of the CNS is tightly regulated, but there are both physiological and pathophysiological circumstances in which the extracellular $\mathrm{pH}$ of the CNS changes (synaptic transmission, cardiac arrest/global ischemia, seizures, and spontaneous or mechanical changes in alveolar ventilation) (Dingledine et al., 1990; Chesler and Kaila, 1992; Andrews et al., 1994). Inhibition of rTASK channels by increased extracellular acidity could lead to depolarization or produce changes in excitability. Potentiation of rTASK currents by increased extracellular $\mathrm{pH}$ during hyperventilation may have importance during ascent to altitude or during control of increased intracranial pressure.

We observed inhibition of rTASK currents after treatment of oocytes with DNP (Table 1). This suggests that rTASK is inhibited by intracellular acidity. However, other consequences of DNP treatment (e.g., reduced intracellular ATP levels, which are known to modulate other potassium channels) may be responsible for this effect. In addition, it is possible that DNP directly modulates rTASK.

The $\mathrm{pH}$ sensitivity of other tandem pore domain $\mathrm{K}^{+}$channel clones has, to some extent, been investigated. Although TOK1 and TWIK-1 are inhibited by intracellular pH, TREK-1 is not (Fink et al., 1996; Lesage et al., 1996a,b). TOK1 has been reported to be insensitive to extracellular $\mathrm{pH}$ over a broad range (Lesage et al., 1996a). In addition, many ATP-sensitive $\mathrm{K}^{+}$channels are inhibited by intracellular acidity (for review, see Traynelis, 1998).

Endogenous $\mathrm{Zn}^{2+}$ is synaptically released after depolarization of neurons, with synaptic concentrations reaching as high as 300 $\mu \mathrm{M}$ (Assaf and Chung, 1984; Howell et al., 1984). We found that $\mathrm{Zn}^{2+}$ within that concentration range significantly inhibited rTASK currents in a voltage-dependent manner. $\mathrm{Zn}^{2+}$ modulates activity of many ligand-gated and voltage-gated ion channels (Winegar and Lansman, 1990; Smart et al., 1994) and can inhibit synaptic transmission in the hippocampus (Xie and Smart, 1991). Although inhibition of voltage-gated potassium channels by micromolar levels of extracellular $\mathrm{Zn}^{2+}$ has been reported (Harrison et al., 1993), our finding of $\mathrm{Zn}^{2+}$ sensitivity of tandem pore domain $\mathrm{K}^{+}$channels is new.

rTASK is the first tandem pore domain $\mathrm{K}^{+}$channel cloned that contains a PSD95, disk-large, zo-1 (PDZ) domain binding site at its $\mathrm{C}$ terminal (T/SXV), suggesting that rTASK may bind to PSD proteins. PSD proteins have been shown to localize to synapses with a number of voltage-gated ion channels, including Kv1.1, Kv1.2, Kv1.4, Kir 2.1, and Kir 2.3, as well as AMPA and NMDA receptors and neuronal nitric oxide synthase (Kim et al., 1995; Kornau et al., 1995; Brenman et al., 1996; Cohen et al., 1996; Dong et al., 1997). The presence of this sequence in rTASK may indicate that it may colocalize with some of these proteins as well. Interestingly, two important inhibitors of rTASK, extracellular $\mathrm{Zn}^{2+}$ and acidity, also potently inhibit some NMDA receptor combinations. By Northern analysis, the highest expression of rTASK within the CNS is in the cerebellum. However, the predominant NMDA receptor expressed in cerebellar granule cells is the NR1/2C subtype, which is the least sensitive to 
extracellular pH (Traynelis et al., 1995) and $\mathrm{Zn}^{2+}$ (Paoletti et al., 1997; Gray et al., in press). Thus, $\mathrm{Zn}^{2+}$ and $\mathrm{pH}$ modulation of synaptic function in the cerebellum may occur via rTASK and not NMDA receptors.

rTASK currents are sensitive to clinical concentrations of the local anesthetics lidocaine and bupivacaine. Inhibition of rTASK by local anesthetics could augment conduction blockade of peripheral nerves by promoting formation of open and inactivated states of voltage-gated sodium channels, making them more sensitive to local anesthetic block (Ragsdale et al., 1994). Indeed, $\mathrm{K}^{+}$ channels similar to rTASK (inhibition by extracellular and intracellular acidity, sensitivity to $\mathrm{Zn}^{2+}$, inhibition by local anesthetics) are expressed by thin myelinated nerves that convey peripheral sensory inputs (Koh et al., 1992; Brau et al., 1995). Inhibition of rTASK may contribute to the CNS (cerebellar and vestibular) symptoms of local anesthetic, phenytoin, or quinidine toxicity. Indeed, rTASK is inhibited by local anesthetics in the range of levels associated with this toxicity $(5-30 \mu \mathrm{M})$.

Intracellular protein kinases seem to produce important modulation of tandem pore domain $\mathrm{K}^{+}$channels. TOK1 and TWIK-1 currents are potentiated by activators of protein kinase $\mathrm{C}$, whereas TREK-1 currents are inhibited (Fink et al., 1996; Lesage et al., 1996a,b). rTASK currents were not altered by the PKC activators PMA or PDBu. Agents that increase intracellular cAMP levels, and thereby activate protein kinase $\mathrm{A}$, have no effect on TOK1 or TWIK-1 currents but significantly inhibit both TREK-1 and rTASK currents (Fink et al., 1996; Lesage et al., 1996a,b). Duprat et al. (1997) reported no effect of forskolin and IBMX treatment on human TASK, whereas we observed inhibition of rTASK. The discrepancy between the two results could be related to clone specificity (human vs rat) or oocyte preparation (possibly different cAMP levels and PKA activity).

In summary, we have cloned and expressed a new tandem pore domain $\mathrm{K}^{+}$channel from rat cerebellum. The open rectification and open probability independent of voltage clearly establishes rTASK as a baseline channel. Its primary sequence contains a PDZ domain at its $\mathrm{C}$ terminal. Its function is regulated by $\mathrm{pH}$, $\mathrm{Zn}^{2+}$, local anesthetics, and activators of protein kinase A. Further experiments will tell with which other cellular proteins rTASK may colocalize and how such a complex may alter the function of excitable tissues.

\section{REFERENCES}

Altschul SF, Gish W, Miller W, Myers EW, Lipman DJ (1990) Basic local alignment search tool. J Mol Biol 215:403-410.

Andrews RJ, Bringas JR, Alonzo G (1994) Cerebrospinal fluid $\mathrm{pH}$ and $\mathrm{PCO}_{2}$ rapidly follow arterial blood $\mathrm{pH}$ and $\mathrm{PCO}_{2}$ with changes in ventilation. Neurosurgery 34:466-470.

Assaf SY, Chung SH (1984) Release of endogenous $\mathrm{Zn}^{2+}$ from brain tissue during activity. Nature 308:734-736.

Brau ME, Nau C, Hempelmann G, Vogel W (1995) Local anesthetics potently block a potential insensitive potassium channel in myelinated nerve. J Gen Physiol 105:485-505.

Brenman JE, Chao DS, Gee SH, McGee AW, Craven SE, Santillano DR, Wu Z, Huang F, Xia H, Peters MF, Froehner SC, Bredt DS (1996) Interaction of nitric oxide synthase with the postsynaptic density protein PSD-95 and alpha1-syntrophin mediated by PDZ domains. Cell 84:757-767.

Chesler M, Kaila K (1992) Modulation of $\mathrm{pH}$ by neuronal activity. Trends Neurosci 15:396-402.

Christie MJ (1995) Molecular and functional diversity of $\mathrm{K}^{+}$channels. Clin Exp Pharmacol Physiol 22:944-951.

Cohen NA, Brenman JE, Snyder SH, Bredt DS (1996) Binding of the inward rectifier $\mathrm{K}^{+}$channel Kir 2.3 to PSD-95 is regulated by protein kinase A phosphorylation. Neuron 17:759-767.
Dingledine R, McBain CJ, McNamara JO (1990) Excitatory amino acid receptors in epilepsy. Trends Pharmacol Sci 11:334-338.

Dong H, O'Brien RJ, Fung ET, Lanahan AA, Worley PF, Huganir RL (1997) GRIP: a synaptic PDZ domain-containing protein that interacts with AMPA receptors. Nature 386:279-284.

Duprat F, Lesage F, Fink M, Reyes R, Heurteaux C, Lazdunski M (1997) TASK, a human background $\mathrm{K}^{+}$channel to sense external $\mathrm{pH}$ variations near physiological pH. EMBO J 16:5464-5471.

Durell SR, Guy HR (1992) Atomic scale structure and functional models of voltage-gated potassium channels. Biophys J 62:238-247.

Fink M, Duprat F, Lesage F, Reyes R, Romey G, Heurteaux C, Lazdunski M (1996) Cloning, functional expression and brain localization of a novel unconventional outward rectifier $\mathrm{K}^{+}$channel. EMBO J 15:6854-6862.

Goldstein SA, Price LA, Rosenthal DN, Pausch MH (1996) ORK1, a potassium-selective leak channel with two pore domains cloned from Drosophila melanogaster by expression in Saccharomyces cerevisiae. Proc Natl Acad Sci USA 93:13256-13261.

Gray AT, Leonoudakis D, Yost CS 1998 An active site histidine of NR1/2C mediates voltage-independent inhibition by zinc. Mol Brain Res, in press.

Hamill OP, Marty A, Neher E, Sakmann B, Sigworth FJ (1981) Improved patch-clamp techniques for high-resolution current recording from cells and cell-free membrane patches. Pflügers Arch 391:85-100.

Harrison NL, Radke HK, Tamkun MM, Lovinger DM (1993) Modulation of gating of cloned rat and human $\mathrm{K}^{+}$channels by micromolar $\mathrm{Zn}^{2+}$. Mol Pharmacol 43:482-486.

Hille B (1992) Ionic channels of excitable membranes, 2nd Edition. Sunderland, MA: Sinauer.

Hodgkin AL, Huxley AF (1952) A quantitative description of membrane current and its application to conduction and excitation in nerve. J Physiol (Lond) 117:500-544.

Howell GA, Welch MG, Frederickson CJ (1984) Stimulation-induced uptake and release of zinc in hippocampal slices. Nature 308:736-738.

Jan LY, Jan YN (1992) Structural elements involved in specific $\mathrm{K}^{+}$ channel functions. Annu Rev Physiol 54:537-555.

Ketchum KA, Joiner WJ, Sellers AJ, Kaczmarek LK, Goldstein SA (1995) A new family of outwardly rectifying potassium channel proteins with two pore domains in tandem. Nature 376:690-695.

Kim E, Niethammer M, Rothschild A, Jan YN, Sheng M (1995) Clustering of Shaker-type $\mathrm{K}^{+}$channels by interaction with a family of membrane-associated guanylate kinases. Nature 378:85-88.

Koh DS, Jonas P, Brau ME, Vogel W (1992) A TEA-insensitive flickering potassium channel active around the resting potential in myelinated nerve. J Membr Biol 130:149-162.

Kornau HC, Schenker LT, Kennedy MB, Seeburg PH (1995) Domain interaction between NMDA receptor subunits and the postsynaptic density protein PSD-95. Science 269:1737-1740.

Kozak M (1996) Interpreting cDNA sequences: some insights from studies on translation. Mamm Genome 7:563-574.

Lesage F, Guillemare E, Fink M, Duprat F, Lazdunski M, Romey G, Barhanin J (1996a) A pH-sensitive yeast outward rectifier $\mathrm{K}^{+}$channel with two pore domains and novel gating properties. J Biol Chem 271:4183-4187.

Lesage F, Guillemare E, Fink M, Duprat F, Lazdunski M, Romey G, Barhanin J (1996b) TWIK-1, a ubiquitous human weakly inward rectifying $\mathrm{K}^{+}$channel with a novel structure. EMBO J 15:1004-1011.

Lesage F, Reyes R, Fink M, Duprat F, Guillemare E, Lazdunski M (1996c) Dimerization of TWIK-1 $\mathrm{K}^{+}$channel subunits via a disulfide bridge. EMBO J 15:6400-6407.

Lesage F, Lauritzen I, Duprat F, Reyes R, Fink M, Heurteaux C, Lazdunski M (1997) The structure, function and distribution of the mouse TWIK-1 K ${ }^{+}$channel. FEBS Lett 402:28-32.

MacKinnon R (1995) Pore loops: an emerging theme in ion channel structure. Neuron 14:889-892.

Methfessel C, Witzemann V, Takahashi T, Mishina M, Numa S, Sakmann B (1986) Patch clamp measurements on Xenopus laevis oocytes: currents through endogenous channels and implanted acetylcholine receptor and sodium channels. Pflügers Arch 407:577-588.

Paoletti P, Ascher P, Neyton J (1997) High-affinity zinc inhibition of NMDA NR1-NR2A receptors. J Neurosci 17:5711-5725.

Quick MW, Lester HA (1994) Methods for expression of excitability proteins in Xenopus oocytes. In: Methods in neuroscience (Conn PM, ed), pp 261-279. San Diego: Academic.

Ragsdale DS, McPhee JC, Scheuer T, Catterall WA (1994) Molecular 
determinants of state-dependent block of $\mathrm{Na}^{+}$channels by local anesthetics. Science 265:1724-1728.

Selyanko AA, Brown DA (1996) Regulation of M-type potassium channels in mammalian sympathetic neurons: action of intracellular calcium on single channel currents. Neuropharmacology 35:933-947.

Smart TG, Xie X, Krishek BJ (1994) Modulation of inhibitory and excitatory amino acid receptor ion channels by zinc. Prog Neurobiol 42:393-441.

Snoeij NJ, van Rooijen HJ, Penninks AH, Seinen W (1986) Effects of various inhibitors of oxidative phosphorylation on energy metabolism, macromolecular synthesis and cyclic AMP production in isolated rat thymocytes. A regulating role for the cellular energy state in macromolecular synthesis and cyclic AMP production. Biochim Biophys Acta 852:244-253.

Traynelis SF (1998) pH modulation of ligand-gated ion channels. In: $\mathrm{pH}$ and brain function (Kaila K, Ransom BR, eds). New York: Wiley.
Traynelis SF, Hartley M, Heinemann SF (1995) Control of proton sensitivity of the NMDA receptor by RNA splicing and polyamines. Science 268:873-876.

Walter P, Lingappa VR (1986) Mechanism of protein translocation across the endoplasmic reticulum membrane. Annu Rev Cell Biol 2:499-516.

Wei A, Jegla T, Salkoff L (1996) Eight potassium channel families revealed by the $C$. elegans genome project. Neuropharmacology $35: 805-829$.

Winegar BD, Lansman JB (1990) Voltage-dependent block by zinc of single calcium channels in mouse myotubes. J Physiol (Lond) 425:563-578.

Woodhull AM (1973) Ionic blockage of sodium channels in nerve. J Gen Physiol 61:687-708.

Xie XM, Smart TG (1991) A physiological role for endogenous zinc in rat hippocampal synaptic neurotransmission. Nature 349:521-524. 